\title{
Infantil Kolik Ayırıcı Tanısında Nadir Bir Neden: Üç Ayllk Bebekte Akut Apandisit
}

\author{
A Rare Cause of Infantile Colic Differential Diagnosis: \\ Acute Appendicitisln A Three Months Old of Infants
}

Bahri Elmas', Turan Yldız'2 Zekeriya ilçe'

${ }^{1}$ Sakarya Üniversitesi Tıp Fakültesi Pediatri AD, Sakarya

${ }^{2}$ Sakarya Üniversitesi Tip Fakültesi Çocuk Cerrahi AD, Sakarya

Correspondence / Yazıșma Adresi:

\section{Yrd. Doç. Dr. Bahri ELMAS}

TC Sağlık Bakanlığı Sakarya Ünv. Eğt. Ve Araşt. Hastanesi

Kadın Doğum ve Çocuk Hastalıkları Merk.

Yenidoğan Mh. Fabrika Cd. Adapazarı/SAKARYA

P: :+905335505351

E-mail: bahrielmas@gmail.com

Geliş Tarihi / Received : 26.04.2017

Kabul Tarihi / Accepted : 07.06.2017

Özet

Akut apandisit çocuklarda en sık acil cerrahi tedavi gerektiren ve hayati tehlike riski bulunan durumdur. Tanı tipik klinik bulgular ile birlikte laboratuvar tetkikleri, ultrason, tomografi veya manyetik rezonans görüntüleme ile konulabilir. Özellikle küçük yaşlarda bulguların nonspesifik olması, çocukların şikayetleri tarifleyememesi veya huzursuzluk nedeni ile batın muayenesinin yeterli sonuç vermemesi tanıyı güçeștirir. Huzursuzluk ve karın șisliği șikayetleri ile 3 gün ara ile iki defa acil servise getirilen ve infantil kolik tanısı konularak herhang bir tedavi uygulanmayan 3 aylık erkek bebek, şikayetlerinin artarak devam etmesi üzerine bir gün sonra yeniden başvurdu. Fizik muayenede batın distandü, WBC $10200 / m m 3$, \%53 lenfosit, $\mathrm{Hb} 9.6 \mathrm{~g} / \mathrm{dl}$, PLT 378000/mm3, CRP $122 \mathrm{mg} / \mathrm{L}$ bulundu. Batın ultrasonografisinde sağ alt kadranda enflamasyonla uyumlu görüntü tespit edildi ancak apandiks görüntülenemedi. Yatısıı yapılarak seftriakson başlandı. Bir gün sonra batında distansiyonu devam eden hastanın WBC 9600/mm3, \%52.6 lenfosit, Hb 8.79g/dl, PLT 370000/mm3, CRP $107 \mathrm{mg} / \mathrm{L}$ bulundu. Batın ultrasonografisinde apandiks çapı $7 \mathrm{~mm}$ ve duvar kalınlığı $2.5 \mathrm{~mm}$, çevrede yoğun inflamasyon bulguları izlendi ve apandisit tanısı konularak apendektomi uygulandı. Histopatolojik incelemede akut apandisit ve peritonit mevcut idi. Huzursuzluk şikayeti ile başvuran infantlarda en sık neden infantil kolik olmakla birlikte organik patolojiler de düşünülmelidir. Akut apandisit çocuklarda bir yaş altında nadir görülmekte ve tipik klinik bulgular çoğunlukla bulunmamaktadır. İnatçı huzurluk ve batında distansiyonu bulunan 6 ay altındaki bebeklerde ayırıcı tanıda akut apandisit de unutulmamalıdır. ( Sakarya Med J 2017, 7(2):109-112 ).

Anahtar Kelimeler: $\quad$ Akut apandisit, infant, infantil kolik

Abstract

Acute appendicitis is the most common form of urgent surgical treatment in children and a life-threatening condition. The diagnosis can be made by laboratory tests, ultrasonography, tomography or magnetic resonance imaging along with typical clinical findings. Especially at younger ages, it is difficult to diagnose that the abdominal examination does not give enough results. The reason for this is that findings are nonspecific, that children can not describe complaints or have discomfort. Infantile colic was diagnosed with a 3-monthold male infant who presented with severe crying and abdominal distention and an emergency clinic with an interval of 3 days. He was reapplied one day after the complaints of the baby who did not receive any treatment continued to increase. Physical examination showed abdominal distention, WBC 10200 / mm3, 53\% lymphocyte, Hb 9.6g / dl, PLT $378000 / \mathrm{mm} 3$, CRP $122 \mathrm{mg} / \mathrm{L}$. Ultrasonography of the abdomen detected the right lower quadrant with inflammation, but the appendix was not visible. He was hospitalized and ceftriaxone was started. One day later, the patient continued abdominal distention, WBC 9600 / mm3, 52.6\% lymphocytes, Hb 8.79g / dl, PLT 370000 / mm3, CRP $107 \mathrm{mg} / \mathrm{L}$. Ultrasonography of the abdomen showed appendiceal diameter of $7 \mathrm{~mm}$ and wall thickness of $2.5 \mathrm{~mm}$, intense inflammation was observed in the environment and appendectomy was performed with appendicitis diagnosis. Histopathological examination revealed acute appendicitis and peritonitis. In infants with irritability and crying reasons, organic pathologies should be considered together with infantile colic as the most common cause. Acute appendicitis is rare in children under one year of age, and typical clinical finding are rarely found. Acute appendicitis should not be forgotten in differential diagnosis of infants under 6 months with persistent peacefulness and abdominal distension. ( Sakarya Tip Dergisi 2017, 7(2):109-112

Keywords Acute appendicitis, infant, infantile colic 


\section{Giriş ve Amaç}

Akut apandisit çocuklarda en sık cerrahi tedavi uygulanan patolojidir. Çocuklarda özellikle 10 yaşından sonra daha sık görülmekle birlikte tüm yaş grubunda görülebilmektedir. Ancak küçük çocuklarda daha az sıklıkla ortaya çıkmaktadır. İnfantlarda \%2.3 sıkıkta,yenidoğanlarda ise oldukça nadir görüldüğü bildirilmektedir $^{1-3}$. Tanı hikaye veklinik bulgular ile birlikte laboratuvar tetkikleri, ultrason, tomografi veya manyetik rezonans görüntüleme ile konulabilir. En sık semptomlariştahsızlık, karın ağrısı, kusma ve devam eden ateş iken en sık bulgular batında hassasiyet ve $38^{\circ} \mathrm{C}$ üzerinde ateştir ${ }^{4,5}$. Özellikle küçük yaşlardaki çocuklarda bulgular nonspesifiktir.Küçük çocukların şikayetlerinitarifleyememesi, huzursuzluk nedeni ile batın muayenesinin yeterli sonuç vermemesi gibi nedenlerle klinik olarak tanısı oldukça zordur. Bulgularıatipik olan küçük çocuklar ve bebekler sıklıkla tanıda gecikme sonucu perforasyon ile başvurmaktadılar. Bu çocuklarda immün sistemin rölatif olarak zayıf olması, tanıda gecikme ile ortaya çıkan komplikasyonlar ve hastane yatış süresinin uzaması nedeniylemorbidite ve mortalitede artış ile karşılaşılmaktadır ${ }^{1}$.

Biz burada akut apandisit nedeni ile opere ettiğimiz üç aylık bebeği klinik ve laboratuvar bulguları eşliğinde sunmayı amaçladık.

\section{Vaka Takdimi}

Huzursuzluk ve karın şişliği şikayetleri ile 3 gün ara ile iki defa acil servise getirilen ve infantil kolik tanısı konularak herhangi bir tedavi uygulanmayan 3 aylık erkek bebek, şikayetlerinin artarak devam etmesi ve ateş şikayetinin de eklenmesi üzerine bir gün sonra yeniden başvurdu. Fizik muayenede ateş $38^{\circ} \mathrm{C}$, nabız $128 / \mathrm{dk}$, solunum $30 / \mathrm{dk}$,huzursuz, solunum sesleri doğal, kalp ritmik, batın distandü idi. WBC 10200/mm3, \%53 lenfosit, Hb 9.6g/dl, PLT $378000 / \mathrm{mm} 3$, CRP $122 \mathrm{mg} / \mathrm{L}$ bulundu. Batın ultrasonografisinde sağ alt kadranda $20 \mathrm{~mm}$ çapında enflamasyonodağı ve çevresinde enflamasyon bulguları tespit edildi,apendiks görüntülenemedi (Resim 1). Yatışı yapılarak seftriakson $50 \mathrm{mg} / \mathrm{kg} /$ gün intravenöz olarak başlandı. Bir gün sonra batında distansiyonu ve ateşi devam eden hastanın WBC 9600/mm3, \%52.6 lenfosit, Hb 8.79g/dl, PLT $370000 / \mathrm{mm} 3$, CRP $107 \mathrm{mg} / \mathrm{L}$ bulundu. Batın ultrasonografisinde apendiks çapı $7 \mathrm{~mm}$ ve duvar kalınlığı $2.5 \mathrm{~mm}$, çevrede yoğun inflamasyon bulguları izlendi (Resim 2). Bulgular perfore apandisit olarak değerlendirildi. Çocuk cerrahi ile konsülte edilen hastayaapendektomi uyguland. Histopatolojik incelemede akut apandisit ve peritonit mevcut idi.Postoperatif ateşleri devam eden hastanın tedavisine metranidazol $30 \mathrm{mg} / \mathrm{kg} /$ gün intravenöz olarak eklendi. Kontrol ultrasonografisinde batın içi apse tespit edilmedi. Yedinci günde şifa ile taburcu edildi.

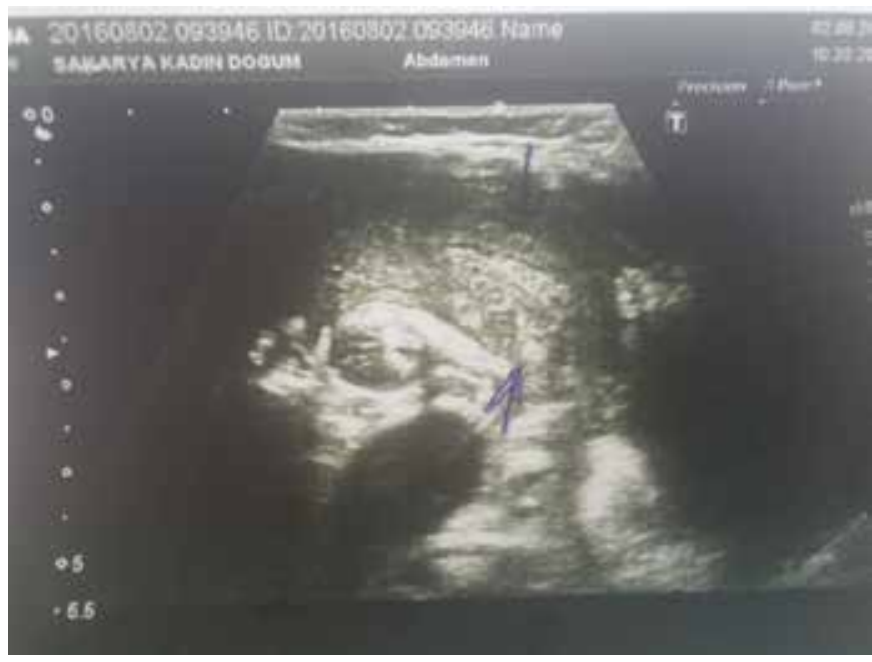

Resim 1: Sağ alt kadranda $20 \mathrm{~mm}$ çapında enflamasyon odağı ve çevresinde enflamasyon bulguları, apendiks görüntülenemedi

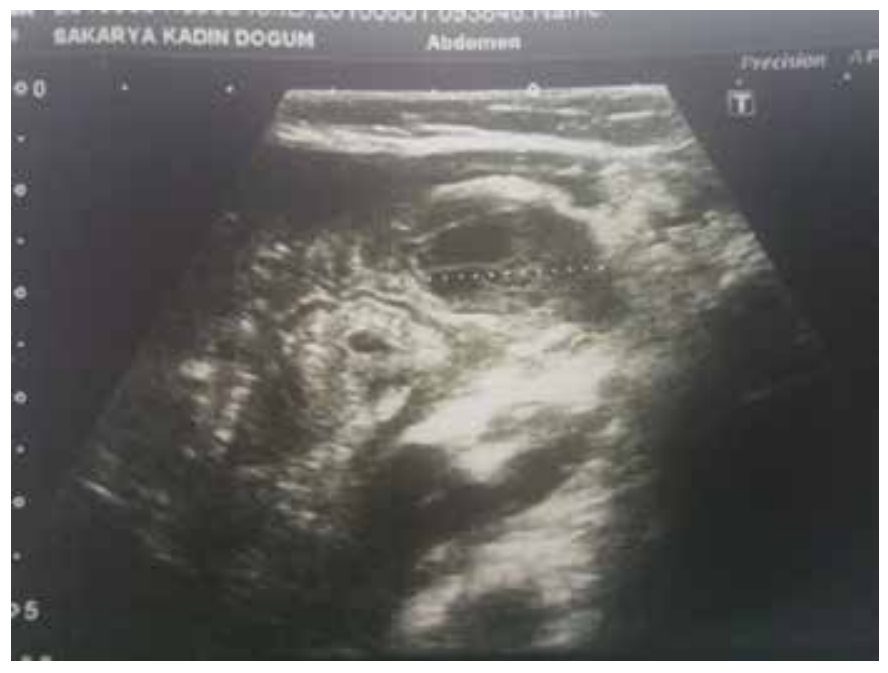

Resim 2: Apendiks çapı $7 \mathrm{~mm}$ ve duvar kalınlığı $2.5 \mathrm{~mm}$, çevrede yoğun inflamasyon bulguları altındaki bebeklerde ayırıcı tanıda akut apandisit de unutulmamalıdır.

\section{Tartışma}

Apandisit infantlarda sık görülmemekle birlikte yenidoğan ve prenatal olarak rastlanılan vakalar bildirilmiştir.Hayatın ilk bir yilında apendiks huni şeklindedir ve lümende obstrüksiyon oluşma riski 
düşüktür ${ }^{2}$. Bu yaş grubunda hastalar genellikle kusma, ishal, huzursuzluk, ateş, inlemeli solunum şikayetleri ile başvururlar ${ }^{3}$. Ateş, kusma ve ardından sağ alt kadrana yayılan periumbilikal ağrı 12 yaş altındaki çocukların $\% 45^{\prime}$ inde görülmektedir ${ }^{7,9}$. Aile veya hasta yaygın karın ağrısı, taşikardi, $37^{\circ} \mathrm{C}$ üzerinde ateş ile birlikte yüzde kızarma gibi atipik semptomlar tarifleyebilir9,10. Konstipasyon, devamında kusma vetipik ishalden daha ziyade sık ve az miktarda yumuşak kıvamlı gaita görülebiliri,10.

Becker ve ark. tarafından yapılan retrospektif çalışmada 3-12 yaş arası 379 hasta incelenmiștir. Bu çalışmada perforasyon oranının 3-6 yaş grubu hastalarda en sık (\%53) olduğu ve hastaların kusma (\%66), ateş (\%47), yumuşak kıvamlı gaita yapma ve huzursuzluk (\%16) şikayetleriile başvurdukları bildirilmiştir ${ }^{4}$. Vakamız da huzursuzluk ve karında şişlik şikayetleri ile üç defa başvurmuş ve ilk iki başvurusunda infantil kolik tanısı almıştır. Son başvurusunda şikayetlerinin artarak devam etmesi ve ateşin de eklenmesi ile apandisit düşünülmüştür.

Horwitz ve ark. tarafından yapılan çalışmada, 11-35 aylık 63 çocukta perforasyon oranının \%84 olduğu, hastaların \%33'ünde diyare bulunduğu ve başlangıç semptomlarından itibaren ortalama gecikme süresinin 4.3 gün olduğu bildirilmektedir ${ }^{5}$. Vakamız Horwitz ve arkadaşlarının çalışma grubuna göre oldukça küçük yaştadır ve dahanadir görülen huzursuzluk ve karın şişliği şikayetleri ile başvurmuștur. Tanıda 4 günlük bir gecikme olmuştur.

Fizik muayene bulguları yaşlara göre değişiklikler gösterir. Yenidoğanlarda bazen sadece huzursuzluk şikayeti bulunabilir. Bu yaş grubunda taşikardik, takipneik olabilir ve sekonder olarak dehidrate görünebilir ${ }^{1,12}$. Alt lop pnömonisini ekarte etmek için solunum sistemi muayenesi, idrar yolu enfeksiyonunu ekarte etmek için idrar tetkiki yapılması gereklidir. Batın muayenesinde tipik bulgular olabileceği gibi bizim vakamızda da olduğu gibi atipik bulgularda bulunabilir ${ }^{8,10}$

Çocuklarda ve özellikle infantlarda akut apandisit tanısında patognomonik bir laboratuvar bulgusu yoktur. Karın ağrısı bulunan ve klinik skorlama ile apandisit düşünülen hastalardan sıklıkla istenen laboratuvar testleri tam kan sayımı, tam idrar tetkiki ve kapsamlı bi- yokimyasal incelemelerdir ${ }^{6}$. Lökosit sayısının tek başına tanısal değeri düşüktür. CRP ile birlikte lökosit sayısının tanıda daha değerli olduğu bildirilmektedir ${ }^{7}$. Tam idrar tetkiki karın ağrısı olan hastalarda apandisit dışındaki tanıları dışlamak için istenmekle birlikte apandisitli hastalarda \% 7-25 oranında piyüri olabileceği bildirilmiştir. Bu nedenle piyüri olması apandisiti ekarte ettirmemektedir ${ }^{8}$. Hastamızda tam idrar incelemesinin yapılmamış olması bir eksikliktir. Bu konuda bebeğin 3 aylık olması nedeni ile idrar toplamadaki güçlüğün bir etken olabileceği düşünülmüştür.

Ultrasonografinin deneyimli radyologlarca yapılması durumunda tanıdaki duyarlllık ve özgüllüğünün \%90-95'e kadar çıkabileceği bildirilmektedir ${ }^{13,16}$. Pozitif ultrason bulguları, sağ alt kadranda komprese edilemeyen 6 mm'den daha büyük tübüler yapıdır ${ }^{16,17}$. Vakamızda ikinci tekrarda apandiks çapı $7 \mathrm{~mm}$ ölçülmüş ve etrafında yoğun enflamasyon bulguları tespit edilerek apandisit tanısı konulmuştur.

Bilgisayarlı tomografi ve manyetik rezonans görüntülemede tanıda kullanılabilecek metotlardandır. Ancak çoğunlukla klinik ve ultrasonografi bulguları ile tanı konulmaktadır ${ }^{18,19}$. Vakamızda da ultrasonografi ile tanı konulduğu için diğer görüntüleme yöntemlerinegerek duyulmamıştır.

Apandisit tanısı konulan hastaların çocuk cerrahisi tarafından konsülte edilmesi, gastrikdekompresyon, intravenöz sIVI, antibiyotik ve ağrı kontrolü için tedavi uygulanması gereklidir. Vakamız çocuk cerrahisi ile konsülte edilerek sıvı ve antibiyotik başlanmıştır. Postoperatif dönemde de ateşlerinin devam etmesi nedeni ile seftriakson tedavisine metranidazol ilave edilmiş ve şifa ile taburcu edilmiştir.

\section{Sonuçlar}

Huzursuzluk şikayeti ile başvuraninfantlarda en sık neden infantil kolik olmakla birlikte organik patolojiler de düşünülmelidir. Akut apandisit çocuklarda bir yaş altında nadir görülmekte ve tipik klinik bulgular çoğunlukla bulunmamaktadır.Inatçı huzursuzluk ve batında distansiyonu bulunan 6 ay altındaki bebeklerde ayırıcı tanıda akut apandisit de unutulmamalıdır. 


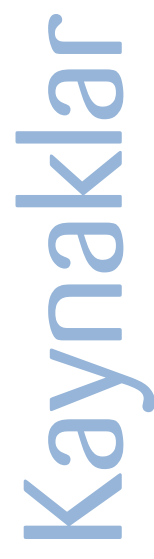

1. Sakellaris G, Tilemis S, Charissis G. Acuteappendicitis in preschool-agechildren. Eur J Pediatr. 2005;164:80-3.

2. Brisighelli G, Morandi A, Parolini F, Leva E. Appendicitis in a 14-month-old infantwithrespiratorysymptoms. Afr J PaediatrSurg. 2012;9:148-51.

3. Serçin Taşar, Medine Ayşin Taşar, Latife Güder, Fatma İnci Arıkan, Yıldız Bilge Dallar, Nihan Ayyıldız Karaman. Çocuk Acil Servisinde Akut Apandisit Tanısı İçin Pediatrik Apandisit Skorlamasının Ve Ultrasonografi Bulgularının Değerleri. Türkiye Çocuk Hastalıkları Dergisi 2015;9:184-188.

4. Nance ML, Adamson WT, Hedrick HL. Appendicitis in theyoungchild: a continuingdiagnosticchallenge. Pediatr EmergCare. 2000;16:160-2.

5. Alloo J, Gerstle T, Shilyansky J, Ein SH. Appendicitis in childrenlessthan 3 years of age: a 28-year review. Pediatr Surgint. 2004;19:777-9.

6. Lin YL, Lee CH. Appendicitis in infancy. Pediatr Surglnt. 2003;19:1-3.

7. Rothrock SG, Pagane J. Acuteappendicitis in children: emergencydepartmentdiagnosisandmanagement. AnnEmergMed. 2000;36:39-51.

8. Narsule CK, Kahle E), Kim DS, Anderson AC, Luks Fl. Effect of delay in presentation on rate of perforation in childrenwithappendicitis. Am J EmergMed. 2011;29:890-3.

9. Bundy DG, Byerley JS, Liles EA, Perrin EM, Katznelson J, Rice HE. Doesthischildhaveappendicitis? JAMA. 2007;298:438-51.

10. Becker T, Kharbanda A, Bachur R. Atypicalclinicalfeatures of pediatricappendicitis. AcadEmergMed. 2007;14:124-9.

11. Horwitz JR, Gursoy M, Jaksic T, Lally KP. Importance of diarrhea as a presentingsymptom of appendicitis in veryyoungchildren. Am J Surg. 1997;173:80-2.

12. Colvin JM, Bachur R, Kharbanda A. Thepresentation of appendicitis in preadolescentchildren. Pediatr EmergCare. 2007;23:849-55.

13. Goldberg LC, Prior J, Woolridge D. Appendicitis in thelnfantPopulation: A Case Report andReview of a Four-MonthOldWithAppendicitis. J EmergMed. 2016;50:765-8.

14. Wang LT, Prentiss KA, Simon JZ, Doody DP, Ryan DP. Theuse of whitebloodcellcountandleftshift in thediagnosis of appendicitis in children. Pediatr EmergCare. 2007;23:69-76.

15. Kwan KY, Nager AL. Diagnosingpediatricappendicitis: usefulness of laboratorymarkers. Am J EmergMed. 2010;28:1009-15.

16. Gracey D, McClure MJ. Theimpact of ultrasound in suspectedacuteappendicitis. ClinRadiol. 2007;62:573-8.

17. Lowe LH, Penney MW, Stein SM, Heller RM, Neblett WW, Shyr Y, Hernanz-Schulman M. Unenhancedlimited CT of the abdomen in thediagnosis of appendicitis in children: comparisonwithsonography. AJR Am J Roentgenol. 2001;176:31-5.

18. Kharbanda AB, Taylor GA, Fishman SJ, Bachur RG. A clinicaldecisionruletoidentifychildren at low risk forappendicitis. Pediatrics. 2005;116:70916.

19. Schneider C, Kharbanda A, Bachur R. Evaluatingappendicitisscoringsystemsusing a prospectivepediatriccohort. AnnEmergMed. 2007;49:77884.

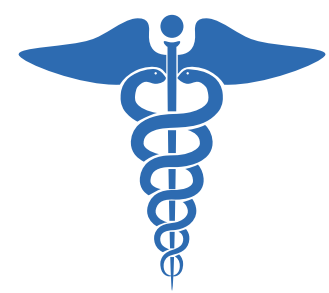

